\title{
The Ventral Part of the Hyoid Gill-Slit and a Mandibular 'Operculum' in some Bony Fishes
}

(1) The hyoid gill-slit. It is commonly accepted that in all living fishes there is no sign of a ventral part of the hyoid (facial) gill-slit that the latter has vanished entirely, and that all that is left of it is a small relic of its dorsal extremity which survives as a spiracle in some primitive forms. Nevertheless, all fishes of the family Malucosteida (Stomiatoidea) have a large, wide open slit between the mandible and the ventral part of the hyoid arch, that is, corresponding exactly to the ventral part of the hyoid (facial) gill-slit. 'The fact itself was known long ago, but was described in somewhat obscure terms, and its signiflcance was overlooked.

Describing this structure in Malacosteus, Günther (1887, p. 215) emphasizes that "it is a perfectly unique structure", and says that it consists of "a thin cylindrical muscular band which connects the hack part of the mandibulary symphysis with the extremity of the hyoid bone". Günther saw the unusually exposed muscles, but did not notice the slits. Zügmayer (1913, pp. 1-2) described the hyoid slits in Malacosteida as the absence of the floor of the mouth ("plancher de la bouche"), which certainly is not exact. Zügmayer's terminology was adopted by later writers, and though Regan and Trewavas (1930, p. 133) noted that in Malacosteidæ "there is no membrane between the lower juw and the hyoid arch", the unique fact of the presence of the ventral part of the livoid gill-slit escaped the notice of morphologists.

In Malacosteidæe the hyoid bar has no gill, and it seems likely that the slit has been secondarily re-acquired. This nay have happened thus. In many teleostean fishes with large jaws and with a highly movable ventral part of the hyoid and branchial arches (pike, hake, turbot, etc.), the wall of the pharyngobranohial cavity between the mandible and the hyoid arch is thin and extensible. In some Stomiatoids (which have much larger jaws than most fishes) the extensibility of this wall and of the muscles between the hyoid bars and the tip of the mandible is extreme, and when the mouth is opened and this wall is extended, the latter appears as a very thin and transparent membrane. When the mouth is shut, this wall is folded up like a curtain hidden between the mandible and the hyoid-bar. III Malacosteidæ, the raundible is even larger than in other Stomiatoids, the exteusibility of the hyoid muscles still greater, and it seems possible that the part of the wall of the branchio-oral cavity between the rami of the mandible and the hyoid bars was perforated; and that thus a hyoid slit secondarily reappeared.

This is a'suggestion only, and is not based on a study of the embryonic development of this slit, which has never been investigated in these fishes.

(2) The mandibular operculum. In Malacosteidæe the mandible extends backwards much farther than usual in fishes, so that a large part of the belly, the chest with the pectoral fins, and the heart, are situated between the rami of the mandible. On the other hand, the "isthmus' and the ventral parts of the hyoid and branchial arches extend much anteriorly and almost reach the symphysis of the mandible, while the dorsal parts of the branchial arches are short. Thus the branchial chambers have an unusually large ventral and anterior extension, and their greater part is situated between the anterior portion of the rami of the mandible. Consequently, the hyomandibular opercles are much reduced and their bony support is very weak: but on the ventral side, between the rami of the mandible, another opercular cover has appeared. This cover consists on each side of a fold along the ventral edge of the mandible extending backwards to the mandibulo-quadrate articulation, then turning round this articulation and passing upwards along the posterior edge of the quadrate to the point where the interhyal is attached to the suspensorium. This fold covers ventrally the space between the mandible and the isthmus. On the lateral side of the isthmus there is another fold extending from the pectoral fin to the anterior end of the isthmus. These two folds 


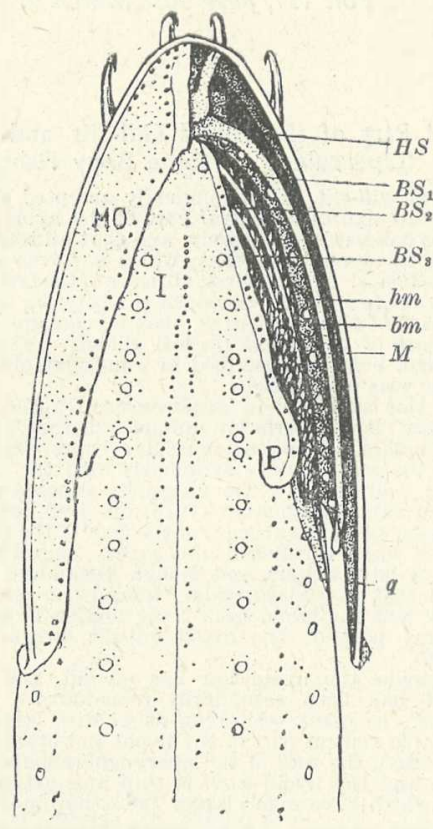

VFNTRAL VIEW (DIAGRAMMaTIC) OF THE HEAD OF A MALACOSTEID (Photosiomias guernei COLIET). THE LEFT MANDIBULAR FOID RHMOVED. T'HE GILL-SLITS ARE SHOWN BLACK. CTRCLES AND DOTS OF DIFFEREN'T SIZE ON THE BODY AND ON THE MANDIBULAR FOJD REPRESENT THE LIGHT ORGANS.

$b m$ : branchiostegal membrine; $B S_{1}, B S_{2}, B S_{3}$; flrst, second and third gill-slits; $h m$ : hyoid muscle; $H S$ : hyoid gill-slit; $I$ : 'isthmus'; $M$ : mandible; $M O$ : mandibular 'Operculum' ; $P$ : rudimentary pectoral fin with a fold extending forwards : $q$ : inner side of the quadrate. The fourth and fifth gill-slits are not visible.

facing each other completely shut from beneath the ventral part of the branchial chamber.

The branchiostegal membrane in Malacosteidæ is low and completely enclosed in the ventral part of the branchial chamber (when the rami of the mandible are not separated). The current of water entering through the hyoid slit reaches the gills freely; and thus this slit in Malacosteida not only corresponds strueturally to a hyoid gill-slit, but to a great extent probably also functions as a gill-slit.

The folds along the edges of the mandible and the quadrate correspond to a mandibular operculum. It is not supported by bones.

It seems of some interest that two such 'Acanthodian' characterg are found in fishes which do not differ in other respects from the 'true' teleosts.

The problems mentioned here will be dealt with fully elsewhere.

British Museum (Natural History), V. TCHERNAFIN. Cromwell Road, London, S.W.7.

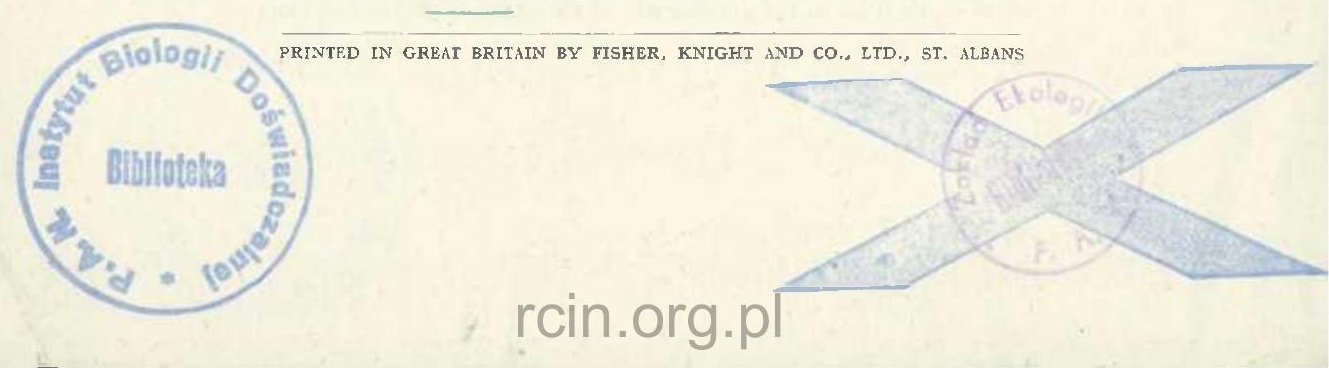

